\title{
DE RESÍDUO A INSUMO: A CONSTRUÇÃO DO CAMINHO PARA UMA QUÍMICA MAIS LIMPA ATRAVÉS DE UM PROJETO DE ENSINO
}

\author{
Regina Felisberto, Lucio Olimpio Vieira, Alessandra Couto, Roselena Schuh, Caroline Thiessen Albino e Daniela \\ Batistela Libardi \\ Curso Técnico em Química, Escola Técnica,Universidade Federal do Rio Grande do Sul, Rua Ramiro Barcelos, 2777, \\ 90035-007 Porto Alegre - RS, Brasil \\ Ana Cristina Borba da Cunha* \\ Curso de Química, Centro Universitário La Salle, Av. Victor Barreto, 2288, 92010-000 Canoas - RS, Brasil
}

Recebido em 28/11/06; aceito em 19/7/07; publicado na web em 19/12/07

\begin{abstract}
FROM RESIDUE TO INPUT: BUILDING A ROAD TO CLEAN CHEMISTRY THROUGH AN EDUCATIONAL PROJECT. The discussion among teachers, students, and technicians about the destination of residues from chemistry laboratories led to a research project whose results were incorporated into a course in its daily practices. The treatment of the residues from argentimetric practices allowed us to establish cognitive relations of technological basis and of those related to the rising of the level of awareness about environmental aspects and social responsibility of chemistry professionals. The techniques and the results, from the economic point of view, namely that of value aggregation (metallic silver) and the conversion of the residue into input (potassium chromate solution) are shown.
\end{abstract}

Keywords: education; argentimetric; residues.

\section{INTRODUÇÃO}

Novas tecnologias originadas do processo de globalização levam à crença de que todo desenvolvimento venha a ser sustentável, de forma que os materiais retirados do meio ambiente sejam completamente aproveitados, considerando a geração dos resíduos e sua utilização.

Inicialmente, acreditava-se que os produtos químicos lançados no ambiente seriam assimilados pela natureza: ou o sistema os transformaria em substâncias de ocorrência natural não prejudiciais, ou os produtos químicos seriam diluídos em tal extensão que não poderiam ser atribuídos aos mesmos quaisquer riscos à vida. A estratégia de que "a solução para a poluição é a diluição" é de fato bem sucedida para alguns poluentes. Porém, no século passado, ficou bem claro que muitos produtos químicos sintéticos não são assimilados porque são persistentes, isto é, não são alterados pela ação de luz, água, ar ou microorganismos (que atuam com freqüência na degradação de muitos poluentes) mesmo passados muitos anos. Exemplos dessas substâncias persistentes incluem pesticidas, como DDT, gases de refrigeração denominados CFCs (clorofluorcarbonetos) e compostos mercuriais. Devido a sua persistência e contínua liberação, as concentrações ambientais de tais substâncias estão aumentando em níveis inquietantes. Além disso, foi descoberto que muitas dessas substâncias não se tornam uniformemente dispersas no meio ambiente. Ao contrário, concentram-se em organismos vivos, podendo atingir seres humanos e outros animais em níveis que, em alguns casos, afetam a saúde e até levam à morte prematura ${ }^{1}$.

Atualmente sabe-se que as indústrias não são as únicas responsáveis pelo quadro atual de contaminação do ambiente por substâncias tóxicas. As universidades, escolas técnicas e institutos de pesquisa também colaboram com esse quadro, mesmo que em pequenas proporções. Considerando que essas instituições exercem papel fundamental quando avaliam os impactos ambientais provoca-

*e-mail: anacunha@unilasalle.edu.br dos por outras unidades geradoras de resíduos, torna-se necessário que os tratem adequadamente, para não verem sua credibilidade comprometida perante a sociedade e os órgãos públicos ${ }^{2}$.

A Universidade Estadual de Campinas fez uma estimativa e constatou que cada aluno que se formava no curso de Química carregava uma triste constatação ao final dos 4 anos de dedicação: para que seus experimentos e testes fossem realizados ao longo do curso, ele gerava uma média de $11 \mathrm{~kg}$ de resíduos químicos ${ }^{3}$. Essa média praticamente se repete em outras universidades e escolas técnicas, levando-se em consideração que a carga horária de aulas práticas é muito semelhante entre essas instituições.

As titrimetrias de precipitação, principalmente o método de Mohr, são procedimentos de análise muito utilizados em laboratórios de graduação, em cursos técnicos e em laboratórios de análise para quantificação de cloretos, brometos e iodetos. Os resíduos dessa análise são sais de prata pouco solúveis e grande quantidade de solução de cromato de potássio.

Devido as suas excelentes propriedades químicas, a prata torna-se cada vez mais indispensável em diversos setores da economia, tais como indústria de fotografia e imagem, indústria química e na fabricação de aparelhos de medida de alta precisão, como a de eletro-eletrônicos.

Frente ao exposto é previsível a formação de resíduos em grande escala. $\mathrm{O}$ descarte inadequado desses resíduos representa sérios riscos para organismos aquáticos e terrestres. Essa preocupação se justifica pelo reconhecido potencial tóxico da prata $^{2,4}$.

A prata é um dos elementos mais nobres encontrados na natureza e que corre o risco de escassez. Diante disso, a cada dia surgem novas pesquisas para recuperação destes resíduos, afinal após sua recuperação podem ser tanto reutilizados num mesmo processo quanto podem se transformar em matéria-prima para outros ${ }^{5}$. Um fator relevante quanto ao descarte é o seu valor agregado, de tal forma que seu descarte implica em prejuízos financeiros.

O cromo é um elemento natural que se encontra em rochas, animais, plantas, solo, ar e em gases vulcânicos. Está presente no meio 
ambiente em diferentes formas, sendo as mais comuns: cromo (0), cromo (III) e cromo (VI). Quanto a sua toxidez, o cromo pode causar danos ao ecossistema, pois é liberado na atmosfera, solo e água durante a manufatura e eliminação de produtos e insumos e na queima de combustíveis fósseis. Certas quantidades podem ser levadas até os corpos d'água, onde o cromo adere a partículas em suspensão que sedimentam, causando a poluição da água e contaminação de peixes e seres humanos através de sua ingestão ${ }^{6}$.

De acordo com a resolução do $\operatorname{CONAMA}^{7} 357$, de março de 2005, resíduos de prata e cromo somente podem se descartados no meio ambiente quando suas concentrações finais forem menores que 0,1 e $0,5 \mathrm{mg} \mathrm{L}^{-1}$, respectivamente. Diversas tentativas de remoção desses metais das soluções residuais já foram feitas por este grupo de trabalho e após quantificação desse material foram detectados limites superiores aos previstos pela legislação.

O presente trabalho constitui-se na síntese da reflexão que vem sendo feita por professores, técnicos e alunos dos cursos técnicos e de graduação em Química.

A idéia de desenvolver projetos com o objetivo de minimizar os riscos apresentados pelos resíduos de laboratório de ensino tem avançado nos últimos anos. A capacidade de refletir criticamente sobre a natureza da ciência e da tecnologia, de buscar o conhecimento através da pesquisa e do debate, do desenvolvimento de técnicas que auxiliem na redução dos riscos químicos e descarte indevido de substâncias e na redução de custos é cada vez mais exigida na formação dos alunos.

Esse projeto ultrapassa os limites de uma turma de alunos, de uma disciplina ou de um professor. Apresenta caráter interdisciplinar e tem continuidade em outras turmas que ingressam no Curso, incorporando, assim, novas idéias e conscientizando os novos alunos da responsabilidade social envolvida na pesquisa científica e tecnológica.

Com o objetivo de conscientizar esses alunos sobre o problema ambiental que está sendo gerado na construção de seu aprendizado, professores e alunos estão planejando, executando e discutindo estratégias de trabalhos que levem à aquisição de determinadas competências vinculadas a conhecimentos específicos e que incentivem o trabalho em equipe, solidário, no qual cada sujeito se considere co-responsável pelo resultado.

Um exemplo da aplicação dessa visão de ensino que busca a educação para a melhor qualidade de vida está relacionado com a recuperação dos resíduos provenientes da quantificação de cloretos pelo método de Mohr (titulação de uma solução neutra do haleto com nitrato de prata em presença de cromato de potássio como indicador).

\section{PROCESSOS DE PURIFICAÇÃO DOS RESÍDUOS DE PRATA E CROMO}

Para realização desse trabalho foi utilizado o resíduo gerado ao longo de vários semestres. O resíduo foi filtrado em papel filtro quantitativo (grycksbo pappersbruk AB-Suécia). O precipitado contendo cloreto e cromato de prata e a solução contendo cromato de potássio e nitrato de potássio foram separados e tratados por diferentes metodologias (recuperação do resíduo contendo prata e recuperação do cromo residual) tornando esse experimento um experimento de Química Limpa.

\section{Pré-tratamento do resíduo contendo prata}

Nessa etapa do trabalho foi avaliada a eficiência do processo de recuperação da prata contida nos resíduos.

O resíduo formado contém cloreto de prata e uma pequena quantidade de cromato de prata, que se encontram na forma de precipitado.
Para tratamento do resíduo sólido foram realizadas duas extrações com solução de ácido clorídrico $10 \%(\mathrm{~m} / \mathrm{v})$ preparada a partir do ácido concentrado com dosagem igual a $37 \%(\mathrm{~m} / \mathrm{m})$. A presença de ácido clorídrico tem como objetivo converter o cromato de prata em cloreto de prata conforme a reação:

$2 \mathrm{Ag}_{2} \mathrm{CrO}_{4(\mathrm{~s})}+4 \mathrm{HCl} \longrightarrow 4 \mathrm{AgCl}_{(\mathrm{s})}+\mathrm{H}_{2} \mathrm{Cr}_{2} \mathrm{O}_{7}+\mathrm{H}_{2} \mathrm{O}$

Para realizar as extrações, $16 \mathrm{~g}$ do resíduo contendo $\mathrm{AgCl}$ foram colocados em um béquer e imersos em solução contendo $30 \mathrm{~mL}$ de ácido clorídrico $10 \%(\mathrm{~m} / \mathrm{v})$ por um período de $24 \mathrm{~h}$. O resíduo foi filtrado, lavado com aproximadamente $50 \mathrm{~mL}$ de água e foi constatado que a água de lavagem apresentava uma coloração amarela, característica da presença de dicromato em solução. Uma nova extração foi realizada e constatou-se que o líquido de lavagem apresentou-se incolor e transparente. A Figura 1 apresenta uma comparação entre a primeira e a segunda extração. O resíduo gerado da extração (60 mL de ácido clorídrico 10\% (m/v) e $100 \mathrm{~mL}$ de água) foi armazenado em frasco específico e enviado para o fluxo de resíduo pois, apesar de não ser visível, pode haver cromato em solução.

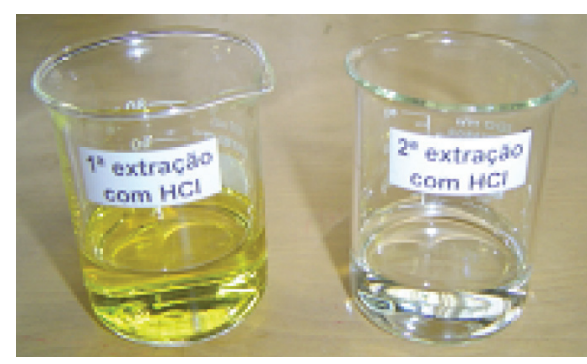

Figura 1. Resíduo de $\mathrm{HCl}$ proveniente da primeira e segunda extração do cromato de prata

\section{Obtenção da prata metálica}

Após a lavagem do resíduo, foi realizada a redução da prata à sua forma metálica utilizando-se o método da dextrose ${ }^{8}$. Este método consiste na reação do cloreto de prata com hidróxido de sódio e dextrose (99,7\% de pureza-Labsynth) a uma temperatura de 70 a $80{ }^{\circ} \mathrm{C}$ durante $15 \mathrm{~min}$.

$2 \mathrm{AgCl}+3 \mathrm{NaOH}+\mathrm{C}_{6} \mathrm{H}_{12} \mathrm{O}_{6} \longrightarrow 2 \mathrm{Ag}^{\circ}+\mathrm{C}_{6} \mathrm{H}_{11} \mathrm{O}_{7} \mathrm{Na}+2 \mathrm{NaCl}+2 \mathrm{H}_{2} \mathrm{O}$

Para cada repetição foram utilizadas amostras de 3,00 a 6,00 g do resíduo de cloreto de prata. Após esse processo a prata metálica obtida foi filtrada, lavada primeiramente com água e após com acetona P.A. (99\% de pureza-F. Maia). O produto permaneceu em repouso até evaporação total da acetona. O processo foi repetido quatro vezes e o produto obtido apresentou aspecto escuro e com pouco brilho.

A simples redução do sal de prata $(\mathrm{AgCl})$ pelo método da dextrose apresentou em sua maioria rendimentos maiores que $100 \%$, o que pode indicar a presença de substâncias contaminantes. Com objetivo de purificar a prata foi utilizada uma fusão com bórax (tetraborato de sódio decaidratado, $\mathrm{Na}_{2} \mathrm{~B}_{4} \mathrm{O}_{7} \cdot 10 \mathrm{H}_{2} \mathrm{O}-99,5 \%$ de pureza-Labsynth).

\section{Fusão com bórax}

Para a purificação da prata o método proposto foi a fusão com bórax (que é o fundente mais apropriado, de acordo com a literatu$\mathrm{ra}^{9}$ ). Com o aquecimento, o bórax perde a água e forma um líquido bastante viscoso, o qual solidifica como um vidro. O bórax, por 
sua propriedade de dissolver os óxidos metálicos ${ }^{10}$, retira da prata o resíduo de cromo, purificando-a.

Essa fusão foi realizada em um cadinho de material cerâmico utilizado em ourivesarias, onde foram colocados a prata reduzida e o bórax. Foi utilizado um bico de Bünsen para fazer um pré-aquecimento do bórax, fazendo com que ele expandisse e contraísse no calor da chama. Com este procedimento, foi possível aumentar a temperatura de entrada do cadinho com bórax no forno para $500{ }^{\circ} \mathrm{C}$. A temperatura foi elevada a $1000{ }^{\circ} \mathrm{C}$ sendo que o tempo necessário para que o forno a atingisse foi de $2 \mathrm{~h}$, esta temperatura mantida por mais $5 \mathrm{~min}$. $\mathrm{O}$ cadinho foi então retirado do forno e mantido em repouso até atingir a temperatura ambiente. Após, o mesmo foi colocado em um copo de béquer contendo ácido clorídrico concentrado suficiente para cobrí-lo e levado ao aquecimento até a dissolução do bórax com a liberação da prata fundida.

Neste trabalho foram realizadas quatro fusões e as recuperações finais encontram-se na Tabela 1.

Tabela 1. Resultados da recuperação da prata metálica após fusão com bórax

\begin{tabular}{lcc}
\hline $\begin{array}{l}\text { Prata Reduzida } \\
(\mathrm{g})\end{array}$ & $\begin{array}{c}\text { Prata Fundida } \\
(\mathrm{g})\end{array}$ & $\begin{array}{c}\text { Recuperação } \\
(\% \mathrm{~m} / \mathrm{m})\end{array}$ \\
\hline 2,8 & 2,1 & $75 \%$ \\
3,8 & 3,1 & $82 \%$ \\
3,0 & 2,8 & $93 \%$ \\
4,2 & 3,5 & $83 \%$ \\
\hline
\end{tabular}

\section{Recuperação do cromato residual}

Essa etapa do trabalho teve como objetivo estabelecer uma metodologia para reaproveitar a solução residual de cromato de potássio como solução indicadora em aulas práticas.

A solução residual de cromato de potássio foi analisada por espectrometria de absorção molecular e apresentou concentração de $650 \mathrm{mg} \mathrm{L}^{-1}$, valor acima do permitido pelo CONAMA ${ }^{7}$ para descarte de efluentes contendo esse metal.

Para nível de comparação com o resíduo, foi preparada uma solução de cromato de potássio $5 \%(\mathrm{~m} / \mathrm{v})$. Essa solução foi diluída duzentas vezes, correspondendo a uma concentração de $250 \mathrm{mg} \mathrm{L}^{-1}$. Foi então construída uma curva de calibração $(\lambda=440 \mathrm{~nm})$, que apresentou coeficiente de correlação $\left(\mathrm{r}^{2}\right)=0,9934$. O valor de absorvância obtido nessas condições foi 0,359 . O resíduo após diluição na proporção de $1: 1$ foi quantificado nessa curva apresentando uma absorbância de 0,467 , o que corresponde a uma concentração final de $650 \mathrm{mg} \mathrm{L}^{-1}$ (aproximadamente 0,07\%).

Para reutilizar essa solução em argentimetria, optou-se pela evaporação do solvente (água) em chapa elétrica até a concentração de $5 \%$ aproximadamente.

$\mathrm{O}$ resíduo apresentava um volume de $5 \mathrm{~L}$. Conhecendo-se a concentração dessa solução foi possível definir até que volume essa solução deveria ser concentrada. Para se obter uma concentração de aproximadamente $5 \%$ foi necessário evaporar o líquido até atingir um volume de $70 \mathrm{~mL}$ de solução aproximadamente.

Da solução evaporada foi retirada uma alíquota, e esta diluída duzentas vezes. A absorvância medida foi 0,318 , o que corresponde a uma concentração de cromato de aproximadamente 4,5\% (m/v).

A utilização da solução de cromato de potássio nessa concentração para quantificações pelo método de Mohr é aceitável.

$\mathrm{O}$ pH medido da solução indicadora de cromato de potássio utilizada como referência foi 8,20, não apresentando diferença significativa com relação ao $\mathrm{pH}$ da solução residual concentrada ( $\mathrm{pH} \mathrm{8,32).}$

Para avaliar a eficiência dessa solução residual foi preparada uma solução padrão de cloreto de sódio $0,0125 \mathrm{~mol} \mathrm{~L}^{-1}$, que foi titulada contra uma solução padronizada de nitrato de prata $0,01221 \mathrm{~mol} \mathrm{~L}^{-1}$.

O resíduo concentrado (solução de cromato de potássio 4,5\%) foi utilizado como indicador do método de Mohr para quantificação de cloretos na solução padrão de cloreto de sódio. A mesma determinação foi feita utilizando-se solução de cromato de potássio $5 \%$ recentemente preparada. Foram feitas cinco determinações e a incerteza foi calculada apenas com base na dispersão dos resultados (tipo A).

As concentrações médias de cloretos encontradas após titulação com solução de $\mathrm{AgNO}_{3}$, utilizando-se solução cromato de potássio $5 \%$ e o resíduo (solução de cromato de potássio aproximadamente $4,5 \%$ ), foram, respectivamente, de $0,0128 \pm 0,0005$ e $0,0133 \pm$ $0,0007 \mathrm{~mol} \mathrm{~L}^{-1}$.

Para validar a utilização do resíduo de cromato de potássio como indicador foi aplicado o teste $t$-student entre os resultados encontrados. $\mathrm{O}$ valor experimental encontrado para esse teste foi 2,24 , valor menor que o tabelado para cinco observações $(2,78)$ com nível de confiança de $95 \%$. Assim foi validada a utilização do resíduo como solução auxiliar em argentimetria.

\section{Cálculo de gastos com materiais e reagentes para recuperação do resíduo}

O cálculo dos custos foi elaborado considerando-se os resíduos gerados em 2 aulas práticas com 20 alunos, o que corresponde a aproximadamente $4 \mathrm{~L}$ de resíduo líquido e $7 \mathrm{~g}$ de resíduo sólido.

Recuperação do cromato de potássio e cloreto de prata

$\mathrm{O}$ tempo gasto para evaporar os $4 \mathrm{~L}$ de solução residual em chapa elétrica foi de $8 \mathrm{~h}$. Considerando que a chapa tem potência de $1500 \mathrm{~W}$, o custo final desse processo foi calculado em $\mathrm{R} \$ 4,00$.

\section{Recuperação do cloreto de prata}

A Tabela 2 apresenta o orçamento de materiais e reagentes necessários para recuperação do resíduo de prata gerado (aproximadamente $7 \mathrm{~g}$ ).

Tabela 2. Orçamento de materiais e reagentes utilizados nesta metodologia

\begin{tabular}{lcc}
\hline Materiais & Quantidade & Gasto $(\mathrm{R} \$)^{*}$ \\
\hline Hidróxido de sódio & $4,0 \mathrm{~g}$ & 0,043 \\
Dextrose & $5,0 \mathrm{~g}$ & 0,079 \\
Bórax & $20,0 \mathrm{~g}$ & 0,22 \\
Acetona & $100 \mathrm{~mL}$ & 1,09 \\
Ácido Clorídrico & $300 \mathrm{~mL}$ & 2,16 \\
Forno & $2 \mathrm{~h}$ & 1,39 \\
Total & - & 4,98
\end{tabular}

* Valores de mercado referentes a setembro de 2006.

O valor total para recuperação e aproveitamento dos resíduos gerados foi de $\mathrm{R} \$ 8,98$.

\section{DISCUSSÃO}

Considerando o valor agregado da prata e o impacto ambiental 
que deixa de ser gerado pela reutilização da solução de cromato de potássio, o projeto proposto mostrou-se viável. Os resultados analíticos obtidos comprovaram a possibilidade da utilização do resíduo de cromato de potássio nas práticas de argentimetria realizadas habitualmente nos cursos de química. No entanto, a proposição da reutilização dessa solução é para fins didáticos.

Os resíduos gerados na recuperação do cromo e da prata foram aproximadamente $200 \mathrm{~mL}$ (entre água de lavagem, HCL com presença de residual de cromato e acetona), volume inferior ao gerado em duas aulas práticas com 20 alunos (4 L de cromato de potássio). Essa redução de resíduo diminui a quantidade armazenada bem como gastos para destino final dos resíduos gerados.

Com relação ao resíduo sólido, verificou-se que a partir de $7 \mathrm{~g}$ é possível obter aproximadamente 5,6 g de prata metálica purificada, se for considerado um rendimento médio de $80 \%$ para esse processo.

O preparo da solução de cromato com vistas a sua reutilização tem um custo estimado de $\mathrm{R} \$ 4,00$, enquanto que a purificação do resíduo de prata, $\mathrm{R} \$ 4,98$, o que totaliza o valor de $\mathrm{R} \$ 8,98$ aproximadamente para execução de todo o processo. Embora o procedimento em sua totalidade tenha algum custo, a recuperação dos resíduos mostrou-se interessante do ponto de vista ambiental e educacional.

O preço de $1 \mathrm{~g}$ de prata varia hoje entre $\mathrm{R} \$ 0,92$ (0,48 dólar) para venda e $\mathrm{R} \$ 0,86(0,45$ dólar) para compra, valor bastante elevado nos últimos seis anos. Considerando-se a especulação de que o metal pode acompanhar os ganhos que o ouro e o cobre registraram nos últimos anos ${ }^{11}$, deve-se considerar seu valor agregado. Além disso, é fundamental o impacto ambiental que deixa de ser gerado pela reutilização da solução de cromato de potássio, de modo que o projeto proposto mostrou-se viável. Deve-se considerar ainda que os alunos têm uma oportunidade ímpar de acompanhar o processo analítico de forma integral, desde a realização do ensaio e geração de resíduos até a transformação destes em insumos.

\section{CONSIDERAÇÕES FINAIS}

Os caminhos trilhados através deste projeto de trabalho têm auxiliado na construção e desenvolvimento de uma forma de pensar a educação química, associando tanto os conhecimentos específicos, quanto o desenvolvimento de competências comportamentais com destaque para os cuidados ambientais.

O relevante é torná-lo não uma repetição a cada ano ou semestre letivo, mas de forma criativa atualizá-lo, tanto do ponto de vista das técnicas quanto sob os aspectos que envolvem o debate sobre o papel da Química no desenvolvimento da sociedade, procurando resgatar o indicado na introdução.

As instituições de ensino, frente à crescente preocupação com o meio ambiente, passam a experimentar um novo desafio. A construção de novos processos de ensino que rompam os limites disciplinares e reaproxime-as das demandas do mundo real. Recuperam assim o papel de formadoras, desenvolvedoras e reforçadoras de competências sociais, destacando aquelas associadas aos compromissos da ciência com a sociedade e melhoria da qualidade de vida.

Os objetivos do projeto foram atingidos. A proposta de trabalhar a recuperação da prata e do cromo permitiu o desenvolvimento das competências profissionais de domínio das bases tecnológicas, as técnicas operacionais, a preocupação ambiental reforçando as relações interpessoais. Internamente passou a sinalizar aos professores a necessidade de otimizar as atividades práticas, substituindo quando possível os reagentes que apresentavam maior poder contaminante do meio ambiente, redimensioná-las para reduzir a quantidade de rejeitos e, como neste exemplo, recuperar os resíduos transformando-os em insumo, minimizando custos financeiros e ambientais.

\section{AGRADECIMENTOS}

Ao Prof. Dr. C. C. Moro, IQ - UFRGS, pela atenção dispensada durante a elaboração deste artigo.

\section{REFERÊNCIAS}

1. Baird, C.; Química Ambiental, 2 ${ }^{\mathrm{a}}$ ed., Artmed: Porto Alegre, 2002.

2. Bendassolli, J. A.; Tavares, G. A.; Ignoto, R. F.; Rosseti, A. L. R. M.; Quim. Nova 2003, 27, 578

3. http://www.unicamp.br/unicamp/unicamp_hoje/sala_imprensa/jornal.html (Jornal da_Unicamp 179, p. 11), acessada em Junho 2004

4. http://www.tabelaperiodica.hpg.ig.com.br/ag.htm, acessada em Dezembro 2006.

5. Amaral, S. T.; Machado, P. F. L.; Peralba, M. C. R.; Santos, T.; Berleze, A. L.; Falcão, H. L.; Martinelli, M.; Gonçalves, R. S.; Oliveira, E. R.; Brasil, J. L.; Araújo, M. A.; Borges, A. C. A.; Quim. Nova 2001, 24, 219.

6. http://www.qca.ibilce.unesp.br, acessada em Setembro 2004.

7. http://www.mma.gov.br/port/conama, acessada em Maio 2006.

8. Murph, J. A.; Ackerman, A. H.; Heeren, J. K.; J. Chem. Educ. 1991, 68, 602.

9. Hutchinson, E.; Los Elementos y sus Reaciones: Una Presentación Rigurosa de la Quimica Genera, 2a ed., Reverté: Barcelona, 1968.

10. Kuya, M. K.; Quim. Nova 1993, 16, 474.

11. http://www.negócios.pt, acessada em Setembro 2006. 